\title{
Intracellular Cystine Loading Inhibits Transport in the Rabbit Proximal Convoluted Tubule
}

Richard F. Salmon and Michel Baum

Department of Pediatrics, University of Texas Southwestern Medical Center at Dallas, Dallas, Texas 75235

\begin{abstract}
Cystinosis is an autosomal recessive disorder characterized by a high intracellular cystine concentration. To establish an in vitro model of this disorder and examine the mechanism of the proximal tubule transport defect seen with elevated intracellular cystine concentrations, rabbit proximal convoluted tubules (PCT) were perfused in vitro. PCTs were loaded with cystine using cystine dimethyl ester, a permeative methyl ester derivative. Bath cystine dimethyl ester $(0.5 \mathrm{mM})$ reduced volume absorption $\left(J_{v}\right)(0.67 \pm 0.07$ to $0.15 \pm 0.09 \mathrm{nl} / \mathrm{mm} \cdot \mathrm{min}, P$ $<0.01)$, bicarbonate transport $\left(J_{\mathrm{TCO}_{2}}\right)(47.2 \pm 4.9$ to $11.1 \pm 2.8$ $\mathrm{pmol} / \mathrm{mm} \cdot \mathrm{min}, P<0.001)$ and glucose transport $\left(J_{\mathrm{GLU}}\right)$ (34.1 \pm 1.5 to $19.7 \pm 1.5 \mathrm{pmol} / \mathrm{mm} \cdot \mathrm{min}, P<0.001)$. The methyl esters of leucine (0.5 mM), and tryptophan (0.5 and $2.0 \mathrm{mM})$ had no effect on these parameters. To examine if intracellular reduction of cystine to cysteine could contribute to the inhibition in transport, the effect of bath cysteine methyl ester on proximal tubular transport was examined. Bath cysteine methyl ester ( 2 but not $0.5 \mathrm{mM}$ ) resulted in an inhibition in $J_{v}$, $J_{\mathrm{GLU}}$, and $J_{\mathrm{TCO}_{2}}$. Cystine dimethyl ester had no effect on mannitol or bicarbonate permeability. These data are consistent with intracellular proximal tubular cystine accumulation resulting in an inhibition of active transport. ( $J$. Clin. Invest. 1990. 85:340-344.) cystinosis • cystine dimethyl ester • Fanconi syndrome
\end{abstract}

\section{Introduction}

Cystinosis is an autosomal recessive disorder characterized by a high intracellular cystine concentration (1-4). The cystine accumulation is localized predominantly in lysosomes $(5,6)$, where a decrease in carrier-mediated efflux of cystine has been described (7-10). This defect eventually leads to the accumulation of cystine in multiple organ systems including the bone marrow, thyroid gland, conjunctival cells, and kidney leading to the Fanconi syndrome (1). Inevitably, these patients develop end-stage renal disease and require dialysis or renal transplantation (2).

The inability to achieve an elevated intracellular concentration of the relatively impermeable amino acid cystine has limited initial investigations into the pathogenesis of cystinosis. However, Goldman and Kaplan (11) and Reeves (12) dem-

Address reprint requests to Dr. M. Baum, Department of Pediatrics, University of Texas Southwestern Medical Center at Dallas, 5323 Harry Hines Boulevard, Dallas, TX 75235.

Received for publication 12 January 1989 and in revised form 5 September 1989

J. Clin. Invest.

(c) The American Society for Clinical Investigation, Inc.

0021-9738/90/02/0340/05 \$2.00

Volume 85, February 1990, 340-344 onstrated that isolated lysosomes could be loaded with amino acids using the permeable methyl ester derivative. Intralysosomal esterases cleave the methyl ester leaving the less permeable amino acid in a high concentration. Thus, the dimethylester of cystine has been used by several investigators to examine the pathogenesis of cystinosis $(7-10,13)$.

Steinherz et al. incubated normal leukocytes with cystine dimethyl ester and demonstrated an increase in abnormal granules using electron microscopy (8). These abnormal granules were lysosomal, whereas nonlysosomal granules remained intact. These authors confirmed that incubation of normal neutrophils with cystine dimethyl ester produced compartmentalization of cystine into lysosomes by demonstrating an almost sevenfold increase in the cystine content of the granular fraction compared with the supernatant fraction of these cells (8). Recently, Foreman et al. showed that renal cortical tubule suspensions incubated with cystine dimethyl ester have an intracellular cystine content comparable to that found in patients with cystinosis whose kidneys were removed at transplantation (14).

The purpose of the present in vitro microperfusion study was to develop an in vitro model of the Fanconi syndrome of cystinosis. Acute cystine loading, using cystine dimethyl ester in the isolated perfused rabbit proximal convoluted tubule (PCT), ${ }^{1}$ resulted in an inhibition in transepithelial potential difference (PD), volume absorption $\left(J_{\mathrm{v}}\right)$, bicarbonate transport $\left(J_{\mathrm{TCO}_{2}}\right)$, and glucose transport $\left(J_{\mathrm{GLU}}\right)$. The inhibition in transport with intracellular cystine loading was not due to an increase in paracellular permeability, but rather to an inhibition of active transport.

\section{Methods}

Isolated segments of randomly dissected midcortical and juxtamedullary rabbit PCTs were perfused as previously described $(15,16)$. Briefly, kidneys from female New Zealand white rabbits were cut in coronal slices and dissected in a cooled $\left(4^{\circ} \mathrm{C}\right)$ ultrafiltrate-like solution containing $115 \mathrm{mM} \mathrm{NaCl}, 25 \mathrm{mM} \mathrm{NaHCO} 3,2.3 \mathrm{mM} \mathrm{Na}_{2} \mathrm{HPO}_{4}, 10$ $\mathrm{mM} \mathrm{Na}$ acetate, $1.8 \mathrm{mM} \mathrm{CaCl}_{2}, 1 \mathrm{mM} \mathrm{MgSO}_{4}, 5 \mathrm{mM} \mathrm{KCl}, 8.3 \mathrm{mM}$ glucose, and $5 \mathrm{mM}$ alanine.

Tubules were perfused with the above ultrafiltrate-like solution and bathed in a similar solution containing $6 \mathrm{~g} / \mathrm{dl}$ albumin. All solutions were bubbled with $95 \% \mathrm{O}_{2}$ and $5 \% \mathrm{CO}_{2}$ at $37^{\circ} \mathrm{C}$ and had a pH of 7.4. The osmolality of the bath and perfusate were adjusted to 290 mos$\mathrm{mol} / \mathrm{kg}$ water by the addition of either $\mathrm{H}_{2} \mathrm{O}$ or $\mathrm{NaCl}$. In order to maintain a constant bath $\mathrm{pH}$ and osmolality, bath fluid was changed continuously at a rate of $0.5 \mathrm{ml} / \mathrm{min}$. All tubules were perfused at $\sim 10$ $\mathrm{nl} / \mathrm{min}$ at $38^{\circ}-39^{\circ} \mathrm{C}$ in a $1.2-\mathrm{ml}$ temperature-controlled bath. The first collection period was begun after an equilibration time of 45-60 min.

1. Abbreviations used in this paper: $J_{\mathrm{GLU}}$, glucose transport; $J_{\mathrm{TCO}}$, bicarbonate transport; $J_{v}$, volume absorption; PCT, proximal convoluted tubule; $\mathrm{PD}$, potential difference; $P_{\mathrm{HCO}_{3}}$, bicarbonate permeability; $P_{\text {mann }}$, mannitol permeability. 
Subsequent periods were separated by an equilibration time of at least 10 min.

Net volume absorption $\left(J_{\mathrm{v}}, \mathrm{nl} \cdot \mathrm{mm}^{-1} \cdot \mathrm{min}^{-1}\right)$ was measured as the difference between the perfused $\left(V_{0}\right)$ and collected $\left(V_{\mathrm{L}}\right)$ rates $(\mathrm{nl} / \mathrm{min})$ normalized per millimeter of tubular length. Exhaustively dialyzed [methoxy- ${ }^{3} \mathrm{H}$ ] inulin was added to the perfusate at a concentration of $50 \mu \mathrm{Ci} / \mathrm{ml}$ so that the perfusion rate could be calculated. The collection rate was measured with a $50-60-\mathrm{nl}$ constant volume pipette. The length and inner diameter of the tubule was measured in millimeters using an eyepiece micrometer.

Net total $\mathrm{CO}_{2}$ flux $\left(J_{\mathrm{TCO}_{2}}, \mathrm{pmol} \cdot \mathrm{mm}^{-1} \cdot \mathrm{min}^{-1}\right)$ was calculated according to the equation: $J_{\mathrm{TCO}_{2}}=\left(V_{0} C_{0}-V_{\mathrm{L}} C_{\mathrm{L}}\right) / \mathrm{L}$, where $C_{0}$ and $C_{\mathrm{L}}$ represent the concentration of $\mathrm{T}_{\mathrm{CO}_{2}}$ in the perfused and collected fluid, respectively. $\mathrm{T}_{\mathrm{CO}_{2}}$ measurements were performed using a microcalorimetry (Picapnotherm, model GVI; World Precision Instruments, Inc., New Haven, CT) (17).

To measure $J_{\mathrm{GLU}}, 50 \mu \mathrm{Ci} / \mathrm{ml}$ of $\left[{ }^{14} \mathrm{C}\right]$ glucose was added to the perfusate. $J_{\mathrm{GLU}}$ was calculated according to the equation: $J_{\mathrm{GLU}}$ $=\left[\left(V_{0} C_{0}^{*}-V_{\mathrm{L}} C_{\mathrm{L}}^{*}\right) / \mathrm{L}\right]\left(G_{0} / C_{0}^{*}\right)$, where $\left[G_{0}\right]$ is the glucose concentration in the perfusate and $C^{*}$ and $C_{\mathrm{L}}^{*}$ are the concentrations of $\left[{ }^{14} \mathrm{C}\right]$ glucose in counts per minute per nanoliter in the perfused and collected fluid respectively. In experiments where bicarbonate and $\left[{ }^{14} \mathrm{C}\right]$ glucose were measured, samples were taken for $\left[{ }^{14} \mathrm{C}\right]$ glucose and $J_{\mathrm{v}}$ alternating with samples for bicarbonate measurement.

The transepithelial PD, in millivolts, was measured by using the perfusion pipette as the bridge into the tubular lumen. The perfusion and bath solutions were connected to the recording and reference calomel half-cells, via a bridge containing an ultrafiltrate of the bathing solution in series with a $3.6 \mathrm{M} \mathrm{KCl} / 0.9 \mathrm{M} \mathrm{KNO}_{3}$ agarose bridge. This arrangement avoided direct contact of $\mathrm{KCl} / \mathrm{KNO}_{3}$ agarose bridges with the solution that bathed the tubule. In addition, the liquid junction potential at the bridge containing ultrafiltrate and the protein-containing bath solution is equal and opposite to the Donnan potential across the tubule. Thus, under these conditions the measured PD is that due to active ion transport (18). In experiments where the perfusate and bathing solutions were not the same, the transepithelial PD was corrected for the measured liquid junction potential. The recording and reference calomel half-cells were connected to the high and low impedance side, respectively, of an electrometer (model 602; Keithley Instruments, Inc., Cleveland, $\mathrm{OH}$ ).

To examine whether cystine dimethyl ester (Sigma Chemical Co., St. Louis, MO) has an effect on proximal tubular transport, tubules were perfused with an ultrafiltrate-like solution and bathed in a serum-like albumin solution during the control period. During the experimental period, $0.5 \mathrm{mM} \mathrm{L-cystine} \mathrm{dimethyl} \mathrm{ester} \mathrm{was} \mathrm{added} \mathrm{to} \mathrm{the}$ bathing solution. $J_{\mathrm{v}}, \mathrm{PD}, J_{\mathrm{TCO}_{2}}$, and $J_{\mathrm{GLU}}$ were measured in the control period and $10 \mathrm{~min}$ after the addition of $0.5 \mathrm{mM}$ L-cystine dimethyl ester. To determine if the methyl esters of other amino acids affected transport, $0.5 \mathrm{mM}$ L-leucine methyl ester $(0.5 \mathrm{mM})$ and L-tryptophan methyl ester $(0.5$ and $2.0 \mathrm{mM}$ ) (Sigma Chemical Co.) were added to the bathing solution in different protocols. To examine the possibility that intracellular cysteine, resulting from the reduction of intracellular cystine, is a potential toxin, $0.5,1$, and $2 \mathrm{mM}$ L-cysteine methyl esters were added to the bathing solution. In each of these protocols, the effect of the amino acid methyl ester on $J_{v}, \mathrm{PD}, J_{\mathrm{GLU}}$, and $J_{\mathrm{TCO}_{2}}$ was examined.

To determine if cystine dimethyl ester inhibited transport by increasing proximal tubule permeability, mannitol and bicarbonate permeabilities $\left(P_{\text {mann }}\right.$ and $\left.P_{\mathrm{HCO}_{3}}\right)$ were measured. PCTs were perfused with a solution containing $10 \mathrm{mM}$ mannitol, $110 \mathrm{mM} \mathrm{NaCl}, 5 \mathrm{mM}$ $\mathrm{NaHCO}_{3}, 5 \mathrm{mM} \mathrm{KCl}, 1 \mathrm{mM} \mathrm{MgSO}_{4}, 1 \mathrm{mM} \mathrm{Na}_{2} \mathrm{HPO}_{4}, 30 \mathrm{mM} \mathrm{Na}$ gluconate, $1.8 \mathrm{mM} \mathrm{CaCl}_{2}$, and $1 \mathrm{mM}$ acetazolamide. The bathing solution was an ultrafiltrate-like solution containing $6 \mathrm{~g} / \mathrm{dl}$ of albumin and $1 \mathrm{mM}$ acetazolamide. $\left[{ }^{14} \mathrm{C}\right] \mathrm{Mannitol}(50 \mu \mathrm{Ci} / \mathrm{ml})$ was added to the perfusate so that $P_{\operatorname{mann}}$ could be calculated. These solutions were designed to give a net $J_{v}$ of zero in the presence of a mannitol and bicarbonate gradient.
$P_{\text {mann }}$ was calculated using the following equation (19):

$$
P_{\operatorname{mann}}=\frac{\frac{M_{0}\left[V_{0}-\left(V_{\mathrm{L}} \cdot C_{\mathrm{L}}^{*} / C_{\delta}^{*}\right)\right]}{\mathrm{L}}}{\frac{M_{0}-\left[M_{0} \cdot\left(C_{\mathrm{L}}^{*} / C_{0}^{*}\right)\right]}{\ln \left[\frac{M_{0}}{\left[M_{0}\left(C_{\mathrm{L}}^{*} / C^{*}\right)\right]}\right]}}
$$

where $M_{0}$ is the concentration of mannitol in the perfusate and $C_{t}^{*}$ and $C_{0}^{*}$ are the concentrations of $\left[{ }^{14} \mathrm{C}\right]$ mannitol in counts per minute per nanoliter in the perfused and collected fluid, respectively. The $P_{\operatorname{mann}}$ was normalized for a $1-\mathrm{mm}$ perfused segment using a luminal radius of $11 \mu \mathrm{m}$ and expressed per apical cylindrical area. Samples were obtained for simultaneous measurements of $\left[{ }^{14} \mathrm{C}\right]$ mannitol and $J_{v}$ and were alternated with $\mathrm{T}_{\mathrm{CO}_{2}}$ collections.

$P_{\mathrm{HCO}_{3}}$ was calculated using the equation:

$P_{\mathrm{HCO}_{3}}=\frac{V_{\mathrm{L}}}{l} \ln \left[\frac{\left(C_{0}-C_{\mathrm{B}}\right)}{\left(C_{\mathrm{L}}-C_{\mathrm{B}}\right)}\right]$

where $C_{0}, C_{\mathrm{L}}$, and $C_{\mathrm{B}}$ represent the concentration of $\mathrm{T}_{\mathrm{CO}_{2}}$ in the perfusate, collected fluid, and bath, respectively (20).

There were at least three measurements of each parameter in a given period for each tubule. The mean values for individual periods in a given tubule were used to calculate the mean value for that period. Data are expressed as a mean \pm SEM. The $t$ test for paired data was used to determine statistical significance.

\section{Results}

The first set of experiments examined the effect of $0.5 \mathrm{mM}$ bath L-cystine dimethyl ester on $J_{\mathrm{v}}, J_{\mathrm{TCO}_{2}}, J_{\mathrm{GLU}}$, and PD. The mean tubular length was $1.9 \pm 0.2 \mathrm{~mm}$ and the perfusion rates were $11.12 \pm 0.27$ and $10.94 \pm 0.33 \mathrm{nl} / \mathrm{min}$ in the control and experimental periods, respectively. Fig. 1 shows the effect of cystine dimethyl ester on $J_{v}$ and PD. $J_{v}$ was $0.67 \pm 0.07$ in the control period and decreased to $0.15 \pm 0.09 \mathrm{nl} \cdot \mathrm{mm}^{-1} \cdot \mathrm{min}^{-1}$ after the addition of cystine dimethyl ester $(P<0.001)$. The transepithelial PD was $-3.2 \pm 0.4$ in the control period and decreased to $-0.4 \pm 0.2 \mathrm{mV}$ after the addition of cystine dimethyl ester $(P<0.001)$. The effect of cystine dimethyl ester on $J_{\mathrm{GLU}}$ and $J_{\mathrm{TCO}_{2}}$ is shown on Fig. 2. $J_{\mathrm{GLU}}$ in the control and experimental periods were $34.1 \pm 1.5$ and $19.7 \pm 1.5$ pmol $\cdot \mathrm{mm}^{-1} \cdot \mathrm{min}^{-1}$, respectively $(P<0.001) . J_{\mathrm{TCO}_{2}}$ was 47.2 \pm 4.9 in the control period and decreased to $11.1 \pm 2.8$ $\mathrm{pmol} \cdot \mathrm{mm}^{-1} \cdot \mathrm{min}^{-1}$ after the addition of cystine dimethyl ester $(P<0.0001)$. These data demonstrate that cystine dimethyl ester inhibits $J_{\mathrm{v}}, \mathrm{PD}, J_{\mathrm{GLU}}$, and $J_{\mathrm{TCO}_{2}}$ in the PCT.

The next experiments were designed to examine if the methyl esters of other amino acids also inhibited transport in the PCT. The effects of L-leucine methyl ester $(0.5 \mathrm{mM})$ and L-tryptophan methyl ester $(0.5$ and $2.0 \mathrm{mM})$ on $J_{\mathrm{v}}$ and PD are shown in Fig. 3. The effects of these methyl esters on $J_{\mathrm{TCO}_{2}}$ and $J_{\mathrm{GLU}}$ are shown in Figs. 4 and 5, respectively.

In experiments examining the effect of L-leucine methyl ester $(n=6)$ on proximal tubular transport, the mean tubular length was $1.5 \pm 0.3 \mathrm{~mm}$. The perfusion rates in the control and experimental periods were $11.01 \pm 0.25$ and $10.54 \pm 0.35 \mathrm{nl} /$ min, respectively. $J_{\mathrm{v}}$ in the control period was $0.64 \pm 0.10$ and $0.58 \pm 0.09 \mathrm{nl} \cdot \mathrm{mm}^{-1} \cdot \mathrm{min}^{-1}$ after the addition of leucine methyl ester $(P=0.29)$. PD was $-3.1 \pm 0.3$ and $-3.5 \pm 0.5 \mathrm{mV}$ in the control and experimental periods, respectively. As shown in Figs. 4 and 5, leucine methyl ester had no effect on $J_{\mathrm{TCO}_{2}}$ and $J_{\mathrm{GLU}}$. 

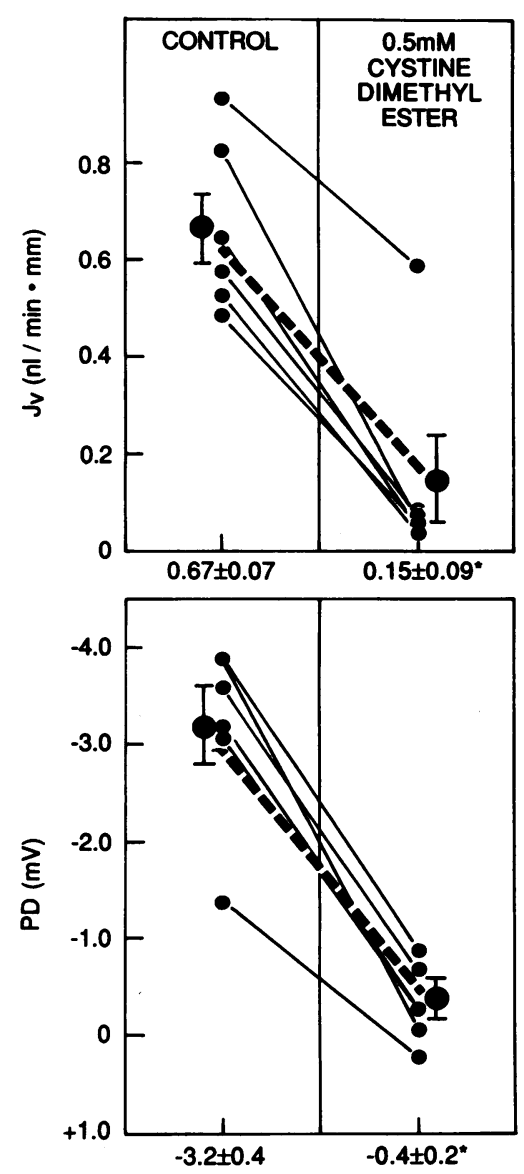

Figure 1. Effect of 0.5 mM bath cystine dimethyl ester on $J_{\mathrm{v}}$ and PD in the PCT. ${ }^{*} P$ $<0.001$.

In experiments examining the effect of $0.5 \mathrm{mM}$ L-tryptophan methyl ester ( $n=5$ in all but $J_{\mathrm{TCO}_{2}}$, where $\left.n=4\right)$ on proximal tubular transport, the tubular length was $1.9 \pm 0.1$ $\mathrm{mm}$. The perfusion rates in the control and experimental periods were $11.34 \pm 0.27$ and $11.04 \pm 0.13 \mathrm{nl} / \mathrm{min}$, respectively. $J_{\mathrm{v}}$ in the control period was $0.58 \pm 0.03 \mathrm{nl} \cdot \mathrm{mm}^{-1} \cdot \mathrm{min}^{-1}$ and $0.58 \pm 0.03 \mathrm{nl} \cdot \mathrm{mm}^{-1} \cdot \mathrm{min}^{-1}$ after the addition of tryptophan methyl ester $(P=0.88)$. PD was $-3.2 \pm 0.7$ and $-3.5 \pm 0.8 \mathrm{mV}$ in the control and experimental periods, respectively. Tryptophan methyl ester $(0.5 \mathrm{mM})$ had no effect on $J_{\mathrm{TCO}_{2}}$ or $J_{\mathrm{GLU}}$ (Figs. 4 and 5).

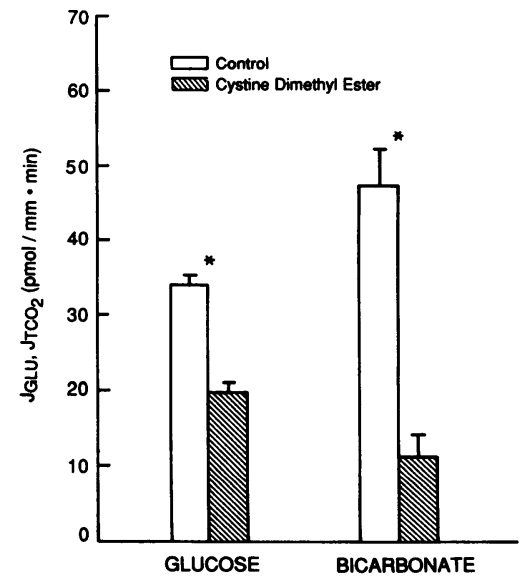

Figure 2. Effect of 0.5 $\mathrm{mM}$ bath cystine dimethyl ester on $J_{\mathrm{GLU}}$ and $J_{\mathrm{TCO}_{2}}$ in the PCT. ${ }^{*} P<0.001$.
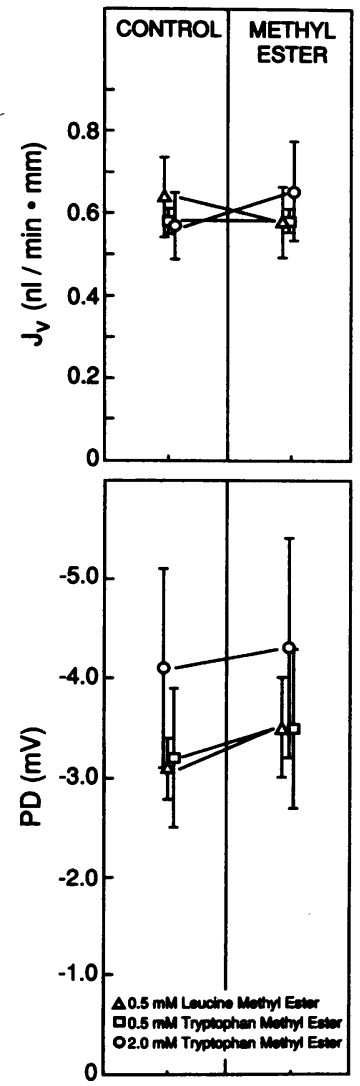

Figure 3. Effect of bath leucine, and tryptophan methyl ester on $J_{\mathrm{v}}$ and PD in the PCT.

To examine if a higher concentration of an amino methyl ester had an effect on proximal tubular transport, $2.0 \mathrm{mM}$ L-tryptophan methyl ester was examined in four tubules. The perfusion rates in the control and experimental periods were $11.01 \pm 0.21$ and $11.19 \pm 0.42 \mathrm{nl} / \mathrm{min}$, respectively, and the mean tubular length was $1.7 \pm 0.2 \mathrm{~mm} . J_{\mathrm{v}}$ was $0.57 \pm 0.08$ in the control period and $0.65 \pm 0.12 \mathrm{nl} \cdot \mathrm{mm}^{-1} \cdot \mathrm{min}^{-1}$ after the addition of $2.0 \mathrm{mM}$ tryptophan methyl ester $(P=0.12)$. PD was $-4.1 \pm 1.0$ and $-4.3 \pm 1.1 \mathrm{mV}$ in the control and experimental period, respectively. $2 \mathrm{mM}$ tryptophan methyl ester had no effect on $J_{\mathrm{GLU}}$ and $J_{\mathrm{TCO}_{2}}$ (Figs. 4 and 5). Thus, neither leucine nor tryptophan methyl ester affected proximal tubular transport, demonstrating that amino acid methyl esters do not have a nonspecific toxic effect on the proximal tubule.

The inhibition in proximal tubular transport resulting from cellular cystine loading could be due to the high concentration of intracellular cystine or potentially to its reduction to cysteine. To examine this possibility, the effect of $0.5,1.0$, and

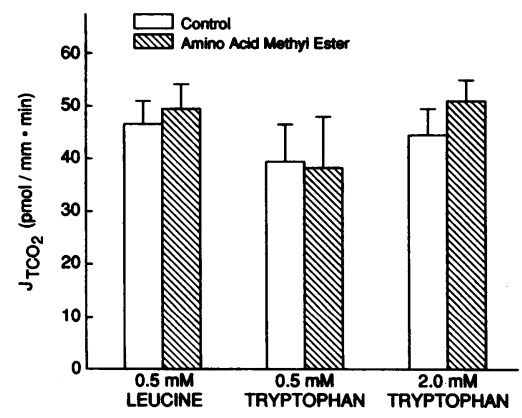

Figure 4. Effect of bath leucine and tryptophan methyl ester on $J_{\mathrm{TCO}_{2}}$ in the PCT. 


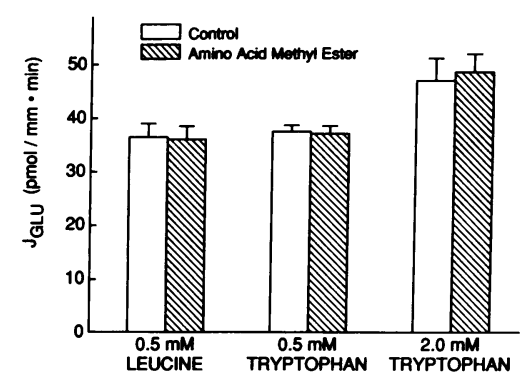

Figure 5. Effect of bath leucine and tryptophan methyl ester on $J_{\mathrm{GLU}}$ in the PCT.

$2.0 \mathrm{mM}$ L-cysteine methyl ester was examined. The results of these experiments are shown in Table I.

In the final protocol, we examined if the effect of cystine dimethyl ester on transport was due to an increase in paracellular permeability. Tubules were perfused with a solution where glucose and alanine were replaced with mannitol and where acetate and $20 \mathrm{mM}$ of bicarbonate were replaced with gluconate. The bathing solution was an ultrafiltrate-like solution containing $6 \mathrm{~g} / \mathrm{dl}$ of albumin. Both the luminal and bathing solutions contained $1 \mathrm{mM}$ acetazolamide. Thus, there was a lumen to bath mannitol and a bath to lumen bicarbonate gradient favoring diffusion. The mean tubular length was $1.7 \pm 0.2 \mathrm{~mm}$ and the luminal diameter was $22 \pm 1 \mu \mathrm{m}$. The perfusion rate in the control period was $8.38 \pm 0.43$ and $8.71 \pm 0.33 \mathrm{nl} / \mathrm{min}$ after the addition of cystine dimethyl ester. The results of these experiments are shown in Table II. Both the $J_{\mathrm{v}}$ and PD were not different from zero in the control period and not affected by cystine dimethyl ester $(n=5)$. As is demonstrated in Table II, cystine dimethyl ester did not affect $P_{\text {mann }}(n=5)$ or $P_{\mathrm{HCO}_{3}}(n=4)$.

\section{Discussion}

This in vitro microperfusion study examined the effect of cystine dimethyl ester on proximal tubular transport in the isolated perfused tubule. Addition of $0.5 \mathrm{mM}$ cystine dimethyl ester to the bathing solution resulted in inhibition of $J_{\mathrm{v}}, J_{\mathrm{GLU}}$, and $J_{\mathrm{TCO}_{2}}$ in the PCT. Addition of the methyl esters of leucine, tryptophan, and cysteine to the bathing solution in the same concentration had no effect. However, $1 \mathrm{mM}$ bath cysteine methyl ester resulted in the inhibition of $J_{\mathrm{v}}$ and $J_{\mathrm{GLU}} .2 \mathrm{mM}$ bath cysteine methyl ester resulted in a greater decrease in the transport of these solutes as well as an inhibition in $J_{\mathrm{TCO}_{2}}$. The addition of cystine dimethyl ester to the bathing solution resulted in no change in epithelial membrane permeability consistent with cystine accumulation resulting in a decrease in active transport. These data demonstrate that cystine dimethyl ester inhibits transport in the PCT, and serves as an in vitro model for examination of the proximal tubular defects seen in cystinosis.

Cystinosis is the most common cause of the Fanconi syndrome in children. However, a model of this disease has been lacking. Recently, studies have demonstrated that intraperitoneal injections of cystine dimethyl ester in Sprague-Dawley rats can produce a diuresis, and an increase in glucose, phosphate, and $\alpha$-amino nitrogen excretion (13). There was no change in creatinine clearance in this model, and there were no histopathological changes in these kidneys demonstrated by either light or electron microscopy (13). In the same study, unperfused renal cortical tubule suspensions were incubated for $10 \mathrm{~min}$ with $2 \mathrm{mM}$ cystine dimethyl ester. This led to a decrease in the uptake of the amino acids L-lysine, L-glycine, and L-taurine and the nonmetabolizable analogue of glucose, $\alpha$-methyl glucoside. In the current study we examined proximal tubule transport directly. Perfusing the tubule with an ultrafiltrate-like solution and bathing the tubule in a serumlike albumin solution allowed evaluation of solute transport in a paired fashion in individual proximal tubules. This study directly demonstrates that intracellular cystine-loading inhibits proximal tubule transport.

In the cystine dimethyl ester model of the Fanconi syndrome, we examined if an increase in proximal tubular permeability was a factor to explain the decrease in net transport. PCTs were perfused with a solution designed to have no net $J_{v}$, and a PD of zero at $38^{\circ} \mathrm{C}$. A lumen to bath mannitol concentration gradient and bath to lumen bicarbonate gradient in the presence of acetazolamide allowed measurement of permeability of both solutes on a paired basis. Addition of cystine dimethyl ester to the bathing solution had no affect on the permeability of mannitol or bicarbonate. Thus, the decreased absorption in this model is due to the inhibition of active transport.

Incubation of tubule suspensions with cystine dimethyl ester led to levels of intracellular cystine comparable to that measured in kidney tissue of cystinotics who had nephrectomies before transplantation $(13,14)$. This level is substantially higher than that found in cultured leukocytes and fibroblasts of patients with cystinosis (2-4). In addition to the marked

Table I. Effect of Cysteine Methyl Ester on Proximal Convoluted Tubule Transport

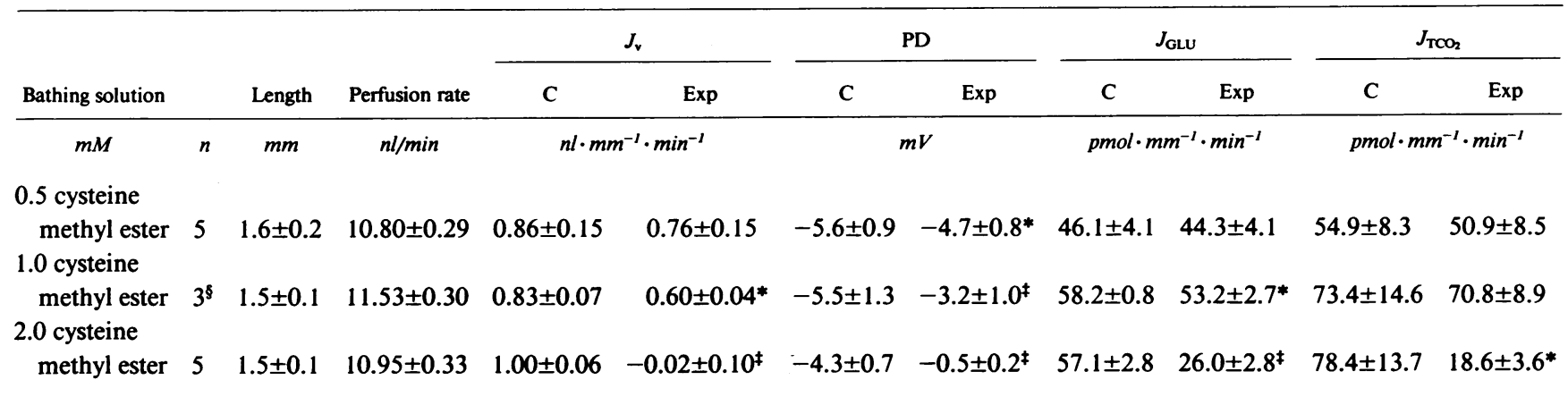

${ }^{*} P<0.05 . \quad{ }^{\ddagger} P<0.01 .{ }^{\S} n=4$ for $V_{0}$, length, and $J_{v}$. 
Table II. Effect of Bath Cystine Dimethyl Ester $(0.5 \mathrm{mM})$ on Proximal Convoluted Tubule Bicarbonate and Mannitol Permeability

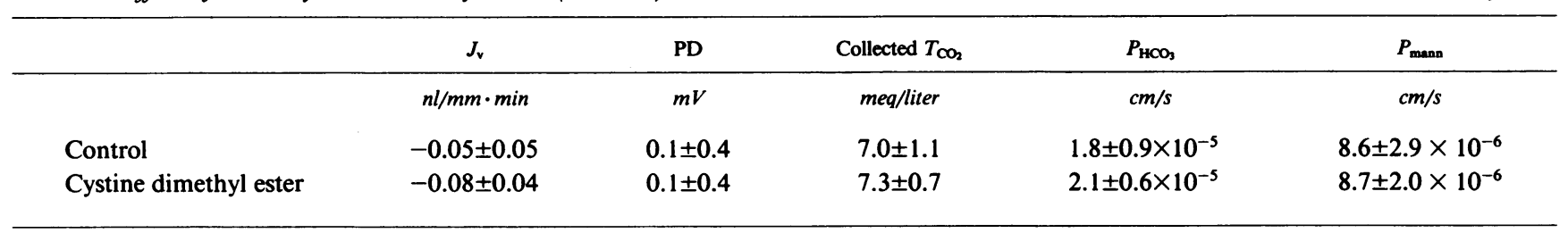

elevation in intracellular cystine, there was about a fivefold increase in cysteine when measured by HPLC (13). Intraperitoneal injections of cystine dimethyl ester in rats, which led to the development of the Fanconi syndrome, resulted in elevated renal cysteine. Neither cystine nor cystine dimethyl ester was present (13). To directly examine whether an elevation in intracellular cysteine can inhibit proximal tubular transport, the effect of bath cysteine methyl ester was examined. $0.5 \mathrm{mM}$ bath cysteine methyl ester caused a small but significant decrease in PD, but no change in $J_{\mathrm{v}}, J_{\mathrm{GLU}}$, or $J_{\mathrm{TCO}_{2}} .1 \mathrm{mM}$ cysteine methyl ester resulted in an inhibition in $J_{\mathrm{v}}, \mathrm{PD}$, and $J_{\mathrm{GLU}} .2 \mathrm{mM}$ cysteine methyl ester caused a greater inhibition in the transport of these solutes as well as an inhibition in $J_{\mathrm{TCO}_{2}}$. This inhibition was not the result of a nonspecific effect of amino acid methyl ester since $2 \mathrm{mM}$ tryptophan methyl ester had no effect on proximal tubule transport.

Cystinosis is characterized by a high intracellular cystine concentration. However, the nephrotoxic compound in this disorder has not been established. Intracellular cystine is most likely the cellular toxin in cystinosis as well as in this in vitro model. The elevated levels of cysteine measured in vivo and in vitro after addition of cystine dimethyl ester may be the result of the reduction of intracellular cystine. The role of intracellular cysteine is unclear but may be of importance. In conclusion, intracellular cystine loading of PCTs with cystine dimethyl ester inhibits active transport and serves as an in vitro model for examining the tubular defects in nephropathic cystinosis.

\section{Acknowledgments}

We are grateful for the technical assistance of Rebecca Aricheta and the able secretarial assistance of Janell McQuinn.

This work is supported by National Institutes of Health grant R29DK-38465-01 and American Heart Association grant 890664.

The assertions contained herein are the private views of the authors and are not to be construed as official or as reflecting the views of the Department of the Navy or the Department of Defense.

\section{References}

1. Gahl, W. A. 1986. Cystinosis coming of age. In Advances in Pediatrics. Year Book Medical Publishers, Inc., Chicago. 33:95-126.

2. Schneider, J. A., and J. D. Schulman. 1982. Cystinosis. In The Metabolic Basis of Inherited Disease. 5th ed. J. B. Stanbury, J. B. Wyngaarden, D. S. Fredrickson, J. L. Goldstein, and M. S. Brown, editors. McGraw-Hill Inc., New York. 1844-1866.

3. Schneider, J. A., K. Bradley, and J. E. Seegmiller. 1967. Increased cystine in leukocytes from individuals homozygous and heterozygous for cystinosis. Science (Wash. DC). 157:1321-1322.

4. Schneider, J. A., F. M. Rosenbloom, K. H. Bradley, and J. E. Seegmiller. 1967. Increased free-cystine content of fibroblasts cultured from patients with cystinosis. Biochem. Biophys. Res. Commun. 29:527-531.

5. Patrick, A. D., and B. D. Lake. 1968. Cystinosis: electron microscopic evidence of lysosomal storage of cystine in lymph node. J. Clin. Pathol. (Lond.). 21:571-575.

6. Schulman, J. D., and K. H. Bradley. 1970. The metabolism of amino acids, peptides, and disulfides in lysosomes of fibroblasts cultured from normal individuals and those with cystinosis. J. Exp. Med. 132:1090-1104.

7. Gahl, W. A., N. Bashan, F. Tietze, I. Bernardini, and J. D. Schulman. 1982. Cystine transport is defective in isolated leukocyte lysosomes from patients with cystinosis. Science (Wash. DC). 217:1263-1265.

8. Steinherz, R., F. Tietze, W. A. Gahl, T. J. Triche, H. Chiang, A. Modesti, and J. D. Schulman. 1982. Cystine accumulation and clearance by normal and cystinotic leukocytes exposed to cystine dimethyl ester. Proc. Natl. Acad. Sci. USA. 79:4446-4450.

9. Gahl, W. A., F. Tietze, N. Bashan, R. Steinherz, and J. D. Schulman. 1982. Defective cystine exodus from isolated lysosome-rich fractions of cystinotic leukocytes. J. Biol. Chem. 257:9570-9575.

10. Gahl, W. A., F. Tietze, N. Bashan, I. Bernardini, D. Raiford, and J. D. Schulman. 1983. Characteristics of cystine counter-transport in normal and cystinotic lysosome-rich leucocyte granular fractions. Biochem. J. 216:393-400.

11. Goldman, R., and A. Kaplan. 1973. Rupture of rat liver lysosomes mediated by L-amino acid esters. Biochim. Biophys. Acta. 318:205-216.

12. Reeves, J. P. 1979. Accumulation of amino acids by lysosomes incubated with amino acid methyl esters. J. Biol. Chem. 254:89148921.

13. Foreman, J. W., M. A. Bowring, J. Lee, B. States, and S. Segal. 1987. Effect of cystine dimethylester on renal solute handling and isolated renal tubule transport in the rat: a new model of the Fanconi syndrome. Metab. Clin. Exp. 36:1185-1191.

14. Goodman, S. I., K. M. Hambidge, C. P. Mahoney, and G. E. Striker. 1973. Renal homotransplantation in the treatment of cystinosis. In Cystinosis. J. D. Schulman, editor. DHEW Publication (NIH), U.S. Government Printing Office, Washington, DC. 225-232.

15. Burg, M., J. Grantham, M. Abramow, and J. Orloff. 1966. Preparation and study of fragments of single rabbit nephrons. Am. J. Physiol. 210:1293-1298.

16. Baum, M. 1987. Insulin stimulates volume absorption in the rabbit proximal convoluted tubule. J. Clin. Invest. 79:1104-1109.

17. Vurek, G. G., D. G. Warnock, and R. Corsey. 1975. Measurement of picomole amounts of carbon dioxide by calorimetry. Anal. Chem. 47:765-767.

18. Berry, C. A., and M. G. Cogan. 1981. Influence of peritubular protein on solute absorption in the rabbit proximal tubule. J. Clin. Invest. 68:506-516.

19. Preisig, P. A., and C. A. Berry. 1985. Evidence for transcellular osmotic water flow in rat proximal tubules. Am. J. Physiol. 249 (Renal Fluid Electrolyte Physiol. 18):F124-F131.

20. Sasaki, S., C. A. Berry, and F. C. Rector, Jr. 1982. Effect of luminal and peritubular $\mathrm{HCO}_{3}^{-}$concentrations and $\mathrm{PCO}_{2}$ on $\mathrm{HCO}_{3}^{-}$ reabsorption in rabbit proximal convoluted tubules perfused in vitro. J. Clin. Invest. 70:639-649. 